\title{
The Study on Electro-hydraulic Proportional Relief Valve of Disc Braking System Based on AMESim
}

\author{
Quanwei Wang ${ }^{1, a}$, Chunlei Zhang ${ }^{2, b}$, Shuang Qiü ${ }^{3, c}$ \\ ${ }^{1}$ College of Mechanical and Electronic Engineering, Shandong University of Science and \\ Technology, Qingdao, 266590, China \\ ${ }^{2}$ College of Mechanical and Electronic Engineering, Shandong University of Science and \\ Technology, Qingdao, 266590, China \\ ${ }^{3}$ College of Mechanical and Electronic Engineering, Shandong University of Science and \\ Technology, Qingdao, 266590, China \\ aemail: 763518973@qq.com, ’email: 764815177@qq.com, cemail:956821113@qq.com
}

\begin{abstract}
Keywords: Disc brake; Electro-hydraulic proportional relief valve; Simulation; AMESim
\end{abstract}
\begin{abstract}
Mine hoist disc braking system, by dynamically adjusting the overflow pressure of the electro-hydraulic proportion relief valve, could control the oil pressure of the disc brake to achieve the safety brake of mine hoist equipment. According to the working features of mine hoist brake system, the author combined with the relevant provisions of the "Coal Mine Safety Regulations" and conducted simulation analysis of the electro-hydraulic proportion relief valve by AMESim software which lays a solid foundation for further research on mine hoist disc braking system.
\end{abstract}

\section{Introduction}

Mine hoist is the important equipment for mining. With the constant advance of mining technology, the mine hoist is being developed into the large-size and efficient equipment. At the same time, due to large load, high speed and the complicated environment, the higher requirement for disc braking system is called for [1] [2]. Electro-hydraulic proportional relief valve, as a valve that can limit pressure of system and release the overload pressure, would continuously control the pressure of braking system with long distance and high precision so as to maintain the stable state when the hydraulic system reaches the set pressure.

\section{The operation overview of disc brake}

The operating principle of electric-hydraulic proportional relief valve. The operating principle of electric-hydraulic proportional relief valve is shown in Figure1 (a), in which ratio electromagnet 1 and pilot valve 2 are on the upper part and main valve 3 is on the lower part. After the input of the signal $u_{g}$ into the ratio electromagnet 1 , it will then generate Electromagnetic force which acts directly on the valve plug of pilot valve 2 through push rod. The oil whose pressure is $\mathrm{P}_{1}$ flows in through the oil cavity to act on the lower end of valve plug of the main valve 3 , and then via the damping hole $R_{1}$ in the main valve plug flows into the upper cavity of the main value plug and the left cavity of the pilot valve 2 to act on the core of the pilot valve 2 . When the system pressure is less than the set electromagnetic force of ratio electromagnet, the pilot valve plug is closed without oil flowing in the valve, so oil pressures in the upper and lower cavities of the main valve are equal and the main valve 3 is closed. When the system pressure surpass the set electromagnetic force of ratio electromagnet, the pilot valve 2 opens, then the pressure via the damping hole $R_{1}$ reduces from $P_{1}$ to $P_{2}$ and the left cavity of the pilot valve 2, via the damping hole $\mathrm{R}_{2}$ is connected to the upper cavity of the main valve 3. Consequently, the pressure difference is engendered between the upper and lower cavities of the main valve 3 . The main valve plug rises, the main valve port opens and the spring force of the main valve increases with the rising degree of opening so as to maintain the system pressure at the set pressure of the ratio electromagnet all the time [3] [4]. Therefore, electric-hydraulic proportional relief valve can control the operating oil 
pressure of system to continuously vary in proportion to the input current signal $u_{\mathrm{g}}$.

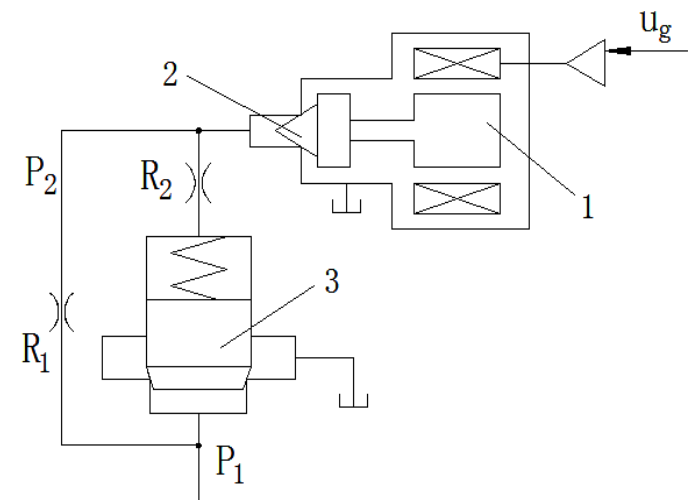

(a)

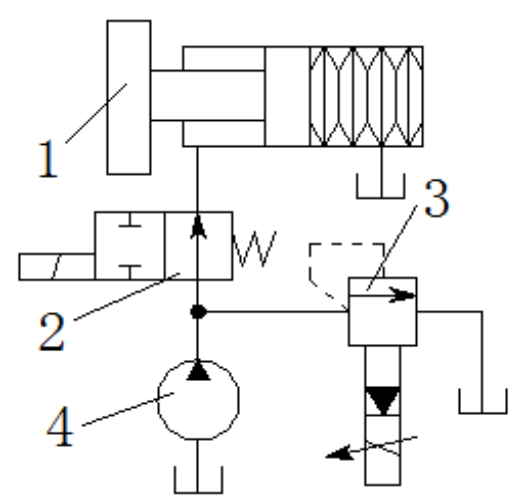

(b)

Fig.1. The operating principle of electric-hydraulic proportional relief valve and the disc braking system of the mine hoist

The operating principle of the disc braking system of the mine hoist. The operating principle of the disc braking system of the mine hoist [5] is shown in Figure1 (b). In the system, when the two-position and two-way reversing valve 2 is power-off, the oil hydraulic pump 4 directly inputs the pressure oil to the disc brake 1 and the oil pressure is controlled by the set pressure of the electric-hydraulic proportional relief valve 3 . When the pressure oil enters into the disc brake, pushing brake shoe to generate space between the brake shoe and brake disc, the brake is in a state of loose. When the two-position and two-way reversing valve 2 is power-on, the oil pressure in the system rises rapidly and the electric-hydraulic proportional relief valve 3 opens and overflow occurs to protect the oil circuit.

\section{AMESim simulation of the disc braking system of the mine hoist}

The establishment of the system model. Taking the disc braking system of a auxiliary shaft of a coal mine in Shandong Province as example, the positive pressure of the disc brake is $306500 \mathrm{~N}$,the rigidity of the Belleville spring $k$ is $4.7 \times 10^{3} \mathrm{~N} / \mathrm{mm}$, the interval of brake shoe is set at $2 \mathrm{~mm}$, the diameter of the oil cylinder is $218 \mathrm{~mm}$, the diameter of the piston rod is $134 \mathrm{~mm}$, and the maximum operating oil pressure is $14 M P_{a}$. The oil pressure rises to $9.5 M P_{a}$ firstly during brake releasing so that the brake shoe can stick on the brake disc in advance. The oil pressure, after a while, increases to its maximum, namely ${ }^{14 M P_{a}}$ to completely release the brake. Therefore, the disc braking system can get the corresponding system operating oil pressure by inputting the continuous and stable current signal into the electric-hydraulic proportional relief valve [6] [7]. AMESim provides a complete platform for the design of system and function by which the user can establish mechanical electro-hydraulic system model of complex multi subjects and on the basis of which it can conduct simulation calculation and further analysis [8]. According to the operating principle of the system, when the AMESim model is established, the system is simplified without the two-position and two-way reversing valve [5], so that it is convenient to analyze the effects of electric-hydraulic proportional relief valve on the disc braking system while working. According to the working principle of the electric-hydraulic proportional relief valve and the disc braking system, the system model is established after its entering into the AMESim environment by using the basic library components of the HCD library, hydraulic library, mechanical library and signal library in the sketch mode, as shown in Figure2. 


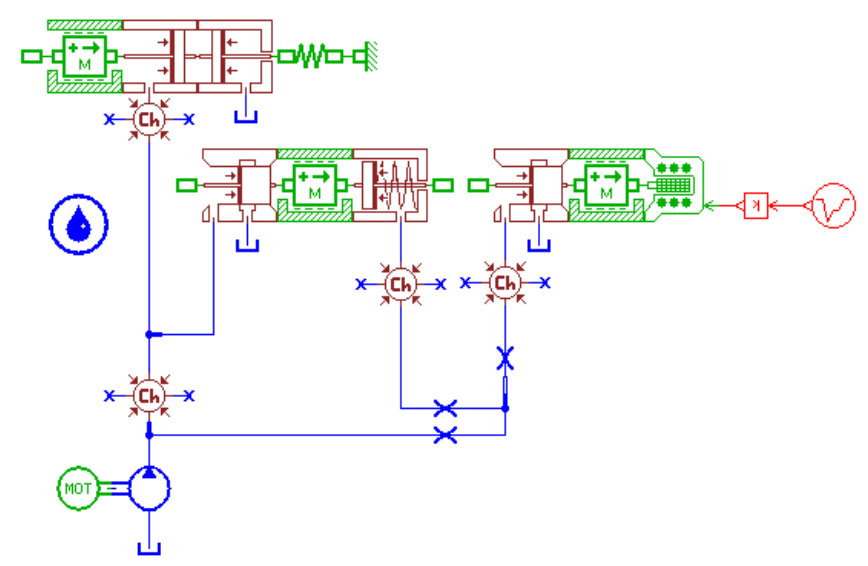

Fig.2. Simulation model of disc braking system

Simulation result and analysis. The simulation results can be obtained when operating as the flowchart. And the pressure at the entrance of the disc brake is shown in Figure3 (a) and the displacement curve of the disc brake shoe is shown in Figure 3 (b).

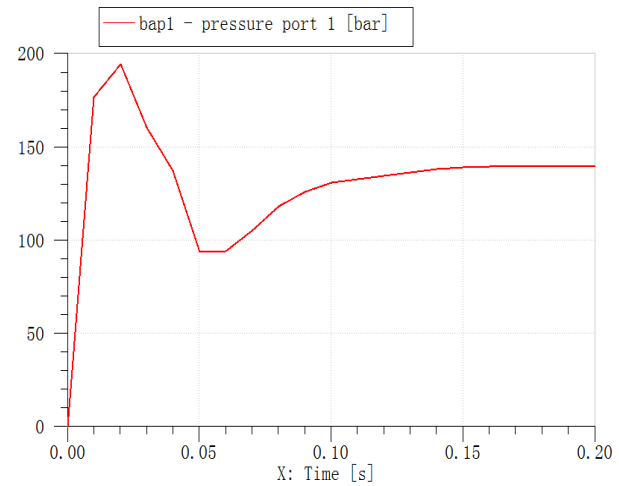

(a)

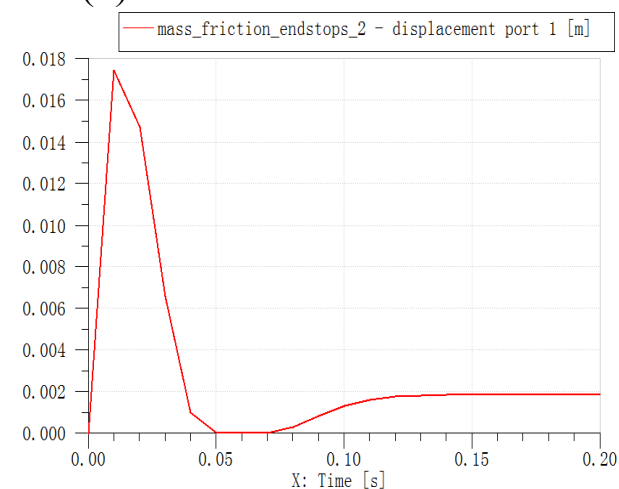

(b)

Fig.3. Simulation result and analysis 1

It can be seen from Figure 3 that the pressure at the entrance of the disc brake suddenly enlarges in a short period of time. It reaches the maximum at the time of $0.02 s$, about ${ }^{19.4061 M P_{a}}$, when the displacement of the brake shoe is $17.4241 \mathrm{~mm}$, which far surpasses the maximum of brake shoe interval of $2 \mathrm{~mm}$ stipulated in the "Coal Mine Safety Regulations". Then the oil pressure declines gradually. At the time of $0.05 \mathrm{~s}$, the oil pressure drops to $9.5 M P_{a}$, and the displacement of the brake shoe is zero. Since then the oil pressure gradually increases, and at the time of about $0.07 \mathrm{~s}$, the brake shoe starts to release the brake disc, while the displacement accordingly increases. When the oil pressure equals the spring force, the displacement reaches $1.8284 \mathrm{~mm}$. At the same time, the pressure at the entrance of the disc brake is about $14 M P_{a}$

The reason that the pressure at the entrance of the disc brake obviously fluctuates is that the input current signal of the electric-hydraulic proportional relief valve changes too rapidly, which causes the abrupt increase of oil pressure and in turn enlarges the displacement of the brake shoe. Although in practice, because of the inertia of disc brake itself and the sudden increase of the oil pressure in a very short time, the displacement of brake shoe may not reach the simulation number. It still is the potential danger of coal mine safety hoisting which requires to be solved in time.

\section{The solution}

Therefore, in order to avoid the potential hazard arising from the abrupt increase of the operating oil pressure in the disc braking system, the time of inputting current signal of the electric-hydraulic proportional relief valve can be properly extended so that the current can steadily increase from zero to the specified value. Since the disc braking system is controlled by PLC, the time of the input current signal of the electric-hydraulic proportional relief valve can be extended to $0.1 s$ when 
programming the PLC and the pressure at the entrance of the disc brake and the displacement of the brake shoe can be concluded as respectively shown in Figure4 (a) and Figure4 (b). What can be seen from the Figure 4 is that when the time of input current signal of the electric-hydraulic proportional relief valve prolongs, the pressure at the entrance of the disc brake does not have obvious fluctuation, meanwhile with increase in the light of proportion and the displacement of the brake shoe also accordingly increases.

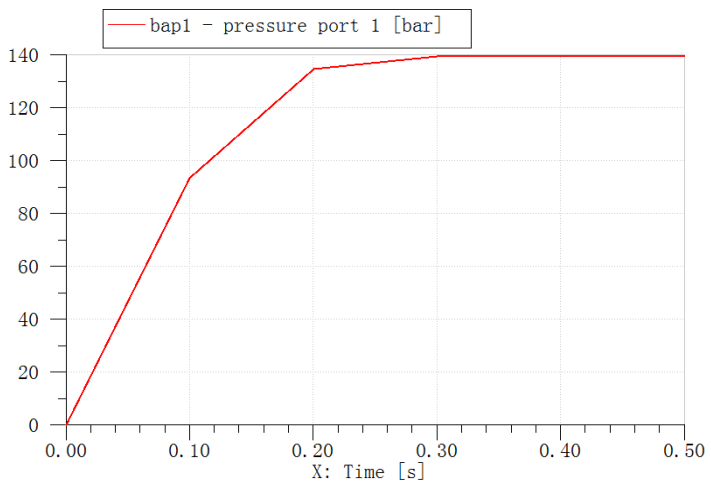

(a)

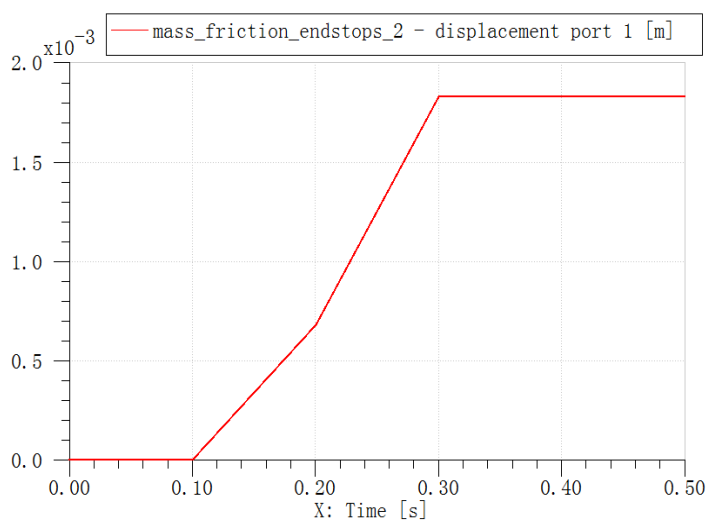

(b)

Fig.4. Simulation result and analysis 2

\section{Conclusion}

(1) For the disc braking system of the mine hoist consisting of the electric-hydraulic proportional relief valve, the system operating oil pressure is related to the input current signal of the overflow valve and its varying time;

(2) The author, by using AMESim software, set up the simulation model of the disc braking system of the mine hoist, conduct the simulation analysis and then get the relations between the braking oil pressure and the displacement of the brake shoe, providing the theoretical basis for improving the braking reliability of mine hoist.

\section{References}

[1] Weijian Chen, Xiuli Qi, Linjing Xiao and Kairu Zhang. Mine transportation and hoisting equipment [M]. China University of Mining and Technology Press. Xuzhou, 2007 (4) 248-249.

[2] Xichun Xie , Xiaohuo Li. Mining machinery and equipment[M].China University of Mining and Technology Press. Xuzhou, 2005 (5) 221-223.

[3] Jun $\mathrm{Wu}$, Bowen Guan and Chi Ma. Simulation and study on electro-hydraulic proportional relief valves of antiskid devices of friction hoists based on AMESim [J]. Mining and Processing Equipment, 200139 (3) 44-46.

[4] Lihuan Gao, Qun Yu and Yongqi Pan. Dynamic analysis of pilot operated proportional relief valve [J]. Journal of China coal society, 20123 (3) 104-106.

[5] Junxia Li, Ziming Kou. Characteristic analysis and simulation study of electricity-liquid proportion overflow valve [J]. Journal of China coal society, 201035 (2) 320-323.

[6] Anle Sang. The principle and applied analysis of ABB hydraulic station [J]. Journal of Huai Nan vocational and technical college, 20077 (7) 11-13.

[7] Guili Lin, Yinwei Yang, Lei Xu. Simulation and analysis of braking system of mine hoist based on AMESim [J]. Coal Mine Machinery, 201031 (4) 41-42.

[8] Jinguo Jiang, Jinwang Yan, Kefei Li. Simulation of Sequence of Y-180 Concrete Pump on AMEsim [J]. Coal Mine Machinery, 2012 33(2) 63-65. 